\title{
Guidelines
}

\section{Diagnosis, Prevention and Treatment of Stable COPD and Acute Exacerbations of COPD: The Swiss Recommendations 2018}

\author{
Daiana Stolz $^{\mathrm{a}}$ Jürg Barandun ${ }^{\mathrm{b}}$ Heinz Borer ${ }^{c}$ Pierre-Olivier Bridevaux ${ }^{\mathrm{d}}$ \\ Patrick Brun $^{\mathrm{e}}$ Martin Brutsche ${ }^{\mathrm{f}}$ Christian Clarenbach ${ }^{\mathrm{g}}$ Christine Eich $^{\mathrm{h}}$ \\ René Fiechter $^{i}$ Martin Frey ${ }^{j}$ Thomas Geiserk Michael Grobl Erich Helfenstein ${ }^{m}$ \\ Lilian Junker $^{\mathrm{n}}$ Malcolm Kohler $^{\mathrm{g}}$ Tsogyal Latshang $^{\circ}$ Armin Lechmann $^{\mathrm{p}}$ \\ Marc Maurer ${ }^{q}$ Laurent Nicod $^{r} \quad$ Franco Quadri $^{\mathrm{s}}$ Daniel Schilter ${ }^{\mathrm{t}}$ Thomas Sigrist $^{\mathrm{j}}$ \\ Paola Soccal ${ }^{\mathrm{u}}$ Philip Tarr ${ }^{\mathrm{v}}$ Robert Thurnheerw Alexander Turk $^{\mathrm{x}}$ Michael Tamm $^{\mathrm{a}}$ \\ a Pulmonary Division, University Hospital Basel, Basel, Switzerland; ${ }^{\mathrm{b}}$ Lungenzentrum Hirslanden, Zurich, Switzerland; \\ 'Bürgerspital Solothurn, Solothurn, Switzerland; dDivision of Pneumology, Hospital du Valais in Sion, Sion, Switzerland; \\ e Berner Reha Zentrum, Berne, Switzerland; ${ }^{\mathrm{L} L u n g e n z e n t r u m, ~ K a n t o n s s p i t a l ~ S t . ~ G a l l e n, ~ S t . ~ G a l l e n, ~ S w i t z e r l a n d ; ~} 9$ Pulmonary \\ Division, University Hospital Zurich, Zurich, Switzerland; h Private Practice, Zurich, Switzerland; iGZO Spital Wetzikon, \\ Wetzikon, Switzerland; 'Klinik Barmelweid, Barmelweid, Switzerland; kPulmonary Division, University Hospital Berne, \\ Berne, Switzerland; 'Spitalzentrum Biel, Biel, Switzerland; ' Lungenpraxis Hirslanden, Klinik St. Anna, Lucerne, Switzerland;

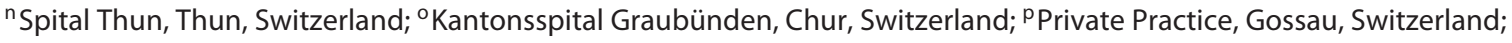

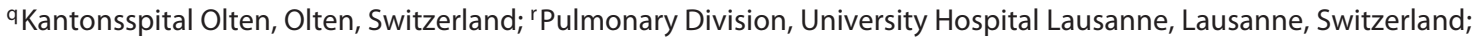

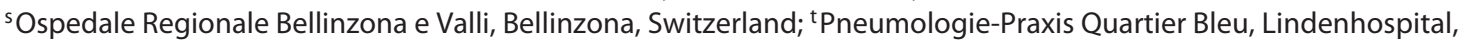

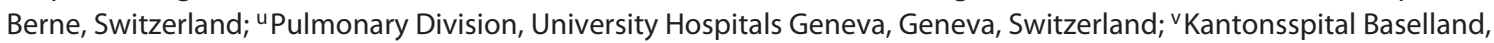 \\ Bruderholz, Switzerland; wSpital Thurgau, Münsterlingen, Switzerland; ${ }^{x}$ See-Spital Horgen, Horgen, Switzerland
}

\section{Keywords}

Chronic obstructive pulmonary disease · Exacerbations .

Swiss · Recommendations · Update · Treatment

\begin{abstract}
The Swiss National Guidelines 2013 for chronic obstructive pulmonary disease have been revised in order to acknowledge recent progress in diagnosis and management of this disease. The resulting new Swiss recommendations are based on best evidence from the literature, the Global Initia-
\end{abstract}

tive for Chronic Obstructive Lung Disease (GOLD) 2018 report and other published national guidelines. Misdiagnosis of chronic obstructive pulmonary disease is common and means that patients do not always receive optimal treatment. To improve the management of patients with chronic obstructive pulmonary disease in Switzerland, these recommendations encourage a more comprehensive assessment of patients, based on the combined assessment of symptoms, degree of airflow limitation, risk of exacerbation and the presence of comorbidities. Recommendations for evidence-based preventive measures, as well as pharmacologi-

\section{KARGER}

(c) 2018 S. Karger AG, Basel

E-Mail karger@karger.com

www.karger.com/res
Daiana Stolz, MPH, FCCP, FERS

Clinic of Respiratory Medicine and Pulmonary Cell Research and

Department of Biomedicine, University Hospital Basel

Hebelstrasse 20, CH-4031 Basel (Switzerland)

E-Mail daiana.stolz@usb.ch 
cal and non-pharmacological strategies for the management of both stable and acute exacerbations of chronic obstructive pulmonary disease are provided in this update.

(c) 2018 S. Karger AG, Basel

\section{Introduction}

National chronic obstructive pulmonary disease (COPD) recommendations are a vital tool to assist health professionals in keeping abreast of the latest medicines and treatment options for patients with the condition. With the advent of many new therapies in the last few years, an update of the 2013 Swiss guidelines is warranted to ensure effective management of patients. The update includes stable COPD and acute exacerbation management recommendations based on the international GOLD Global Strategy for the Diagnosis, Management and Prevention of COPD 2018 report, published online on the GOLD website, as well as best evidence from the literature and other published national guidelines in Europe (Table 1). The updated GOLD 2018 report published broader inclusion criteria, which means there may be more patients affected by COPD than previously diagnosed.

Based on the GOLD 2018 report, this update incorporates a new definition of COPD, as well as an updated $\mathrm{ABCD}$ assessment tool that enables inclusion of a broader patient population. A personalized approach is advocated. As before, this update recommends evaluation for COPD in individuals with a history of risk factors or with dyspnea, chronic cough, or sputum production, using a post-bronchodilator forced expiratory volume in one second/forced vital capacity $\left(\mathrm{FEV}_{1} / \mathrm{FVC}\right)$ cut off ratio less than $70 \%$ for diagnosis. However, the role of spirometry in the overall management of COPD is amended to include a combined assessment that separates symptoms, exacerbation history and the patient's overall health. Pharmacotherapy changes for stable COPD have been updated to reflect the latest randomized controlled trial data, which confirms the benefits of fixed dose triple bronchodilator therapy in stable COPD patients. Another addition to these recommendations is a slight change in the definition of an exacerbation, which is simplified and more practical for the clinical setting. Non-drug interventions and lifestyle measures such as smoking cessation programs, vaccinations and pulmonary rehabilitation is recommended, and usage of these resources should be maximized in all COPD patients.

Diagnosis, Prevention and Treatment of Stable COPD

\section{Definition}

COPD is characterized by persistent respiratory symptoms and airflow limitation that is due to airway and/or alveolar abnormalities usually caused by significant exposure to noxious particles or gases [12]. The revised GOLD definition of COPD, endorsed by both the American Thoracic Society and the European Respiratory Society (ERS), takes into consideration the impact of respiratory symptoms and the role of lung tissue and airway abnormalities in the development of COPD [12].

\section{Burden of Disease}

Although COPD is largely a preventable and treatable disease, analysis of the incidence of respiratory symptoms shows that COPD is a major disease burden in Europe [13]. It is often underdiagnosed or misdiagnosed in Swiss primary care and hence prevalence and mortality figures are significantly underestimated [14, 15]. Measured airflow obstruction prevalence of up to $10 \%$ for adult patients (GOLD stage $\geq 2$ ) is estimated in the Swiss Study on Air Pollution and Lung Diseases in Adults (SAPALDIA) cohort [16]. This study also shows that the prevalence of COPD is largely age dependent.

Mortality from COPD accounts for almost $50 \%$ of all respiratory disease deaths in Switzerland [17]. Approximately $2.6 \%$ of all hospitalizations are related to COPD in Swiss patients [14]. Cigarette smoking is the most common risk factor for COPD, but other environmental exposures and host factors may contribute (e.g., occupational exposures, biomass fuels, $\alpha 1$-antitrypsin deficiency) [12]. Individual susceptibility to infections plays a role in exacerbations [12].

COPD is a debilitating and chronic disease that carries a significant and substantial socioeconomic burden on individuals and society. Direct COPD-related costs increase with disease severity. In Sweden, direct costs from COPD are reported as EUR 7,320 for mild, EUR 8,280 for moderate, EUR 9,230 for severe and EUR 11,810 for very severe disease [18]. Indirect costs such as the inability to work may be affected in individuals with the disease [18]. In 2012, the average income of a Swedish COPD patient was less than half of what a nonCOPD patient earns (EUR 11,500 vs. EUR 29,000 in 2012) [18]. 
Table 1. Overview of European national clinical practice guidelines on chronic obstructive pulmonary disease published from 2007

\begin{tabular}{|c|c|c|c|c|}
\hline Country & Organization & Title of guidelines & $\begin{array}{l}\text { Number } \\
\text { of pages }\end{array}$ & $\begin{array}{l}\text { Year of } \\
\text { publication }\end{array}$ \\
\hline England/Wales & $\begin{array}{l}\text { National Institute for Health and } \\
\text { Clinical Excellence (NICE) }\end{array}$ & $\begin{array}{l}\text { Chronic obstructive pulmonary disease } \\
\text { in over 16s: diagnosis and } \\
\text { management (CG101) }\end{array}$ & 62 & $2010[1]$ \\
\hline Germany & $\begin{array}{l}\text { German Respiratory Society and } \\
\text { German Society for Pneumology and } \\
\text { Respiratory Medicine }\end{array}$ & $\begin{array}{l}\text { Guidelines for the diagnosis and } \\
\text { therapy of COPD }\end{array}$ & 40 & $2007[2]$ \\
\hline France & $\begin{array}{l}\text { Société de Pneumologie de Langue } \\
\text { Française }\end{array}$ & $\begin{array}{l}\text { Recommendation for the clinical } \\
\text { practice management of COPD }\end{array}$ & 27 & $2010[3]$ \\
\hline The Netherlands & $\begin{array}{l}\text { Dutch College of General } \\
\text { Practitioners (NHG) }\end{array}$ & $\begin{array}{l}\text { The NHG guidelines "Adult asthma" } \\
\text { and "COPD" }\end{array}$ & & $2015[4]$ \\
\hline Finland & $\begin{array}{l}\text { The Finnish Medical Society } \\
\text { Duodecim }\end{array}$ & $\begin{array}{l}\text { Diagnosis and pharmacotherapy of } \\
\text { stable chronic obstructive pulmonary } \\
\text { disease: the Finnish guidelines }\end{array}$ & 17 & $2015[5]$ \\
\hline Poland & Polish Respiratory Society & $\begin{array}{l}\text { Polish respiratory society guidelines } \\
\text { for chronic obstructive pulmonary } \\
\text { disease }\end{array}$ & 37 & $2014[6]$ \\
\hline Italy & $\begin{array}{l}\text { AIMAR (Interdisciplinary } \\
\text { Association for Research in Lung } \\
\text { Disease), AIPO (Italian Association } \\
\text { of Hospital Pulmonologists), SIMER } \\
\text { (Italian Society of Respiratory } \\
\text { Medicine), SIMG (Italian Society } \\
\text { of General Medicine) }\end{array}$ & $\begin{array}{l}\text { The clinical and integrated } \\
\text { management of COPD }\end{array}$ & 19 & 2014 [7] \\
\hline Spain & $\begin{array}{l}\text { Spanish Society of Pulmonology and } \\
\text { Thoracic Surgery } \\
\text { (SEPAR) }\end{array}$ & $\begin{array}{l}\text { Spanish guideline for COPD } \\
\text { (GesEPOC). Update } 2014\end{array}$ & 16 & $2014[8]$ \\
\hline Czech Republic & $\begin{array}{l}\text { Czech Pneumological and } \\
\text { Phthisiological Society }\end{array}$ & $\begin{array}{l}\text { Chronic Obstructive Pulmonary } \\
\text { Disease: official diagnosis and } \\
\text { treatment guidelines of the Czech } \\
\text { Pneumological and Phthisiological } \\
\text { Society; a novel phenotypic approach } \\
\text { to COPD with patient-oriented care. }\end{array}$ & 13 & 2013 [9] \\
\hline Portugal & Health Ministry, Portugal & $\begin{array}{l}\text { Diagnosis and Treatment of Chronic } \\
\text { Obstructive Pulmonary Disease }\end{array}$ & 15 & $2011[10]$ \\
\hline Switzerland & Swiss Respiratory Society & $\begin{array}{l}\text { Diagnosis and Management of } \\
\text { Chronic } \\
\text { Obstructive Pulmonary Disease: } \\
\text { The Swiss Guidelines }\end{array}$ & 15 & $2013[11]$ \\
\hline
\end{tabular}

\section{Diagnosis}

The diagnostic process for COPD should be multidimensional and include a detailed medical history, physical examination and measurement of airflow obstruction. Prompt and accurate diagnosis enables early intervention, therefore, according to the most recent GOLD strat- egy, a diagnosis of COPD should be considered in any patient with a history of exposure to risk factors (e.g., tobacco smoking) and/or with dyspnea (progressive, on exertion or persistent), chronic cough or sputum production [12]. Post-bronchodilator spirometry $\left(\mathrm{FEV}_{1} / \mathrm{FVC}\right.$ ratio $<70 \%$ ) is required for confirmation of a diagnosis [12]. Confirm with repeated spirometry measurements 
the absence or presence of airflow obstruction in patients with an $\mathrm{FEV}_{1} / \mathrm{FVC}$ ratio between 60 and $80 \%$, as this ratio may change due to biological variability [12].

\section{Medical History}

A focused history should be collected in patients with suspected COPD and should include (1) key symptoms such as dyspnea, chronic cough, and sputum production; (2) smoking habits (including quantification of cumulative smoking history, that is, how many packs per year); (3) exposure to other risk factors (i.e., occupational or environmental exposures); (4) past medical history, including asthma and respiratory infections in childhood; (5) family history of COPD or other chronic respiratory disease; (6) pattern of symptom development; (7) history of exacerbations or previous hospitalizations for respiratory disorders; (8) presence of comorbidities, (9) impact of disease on patient's life; (10) opportunities for reducing risk factors (e.g., smoking cessation); and (11) family and social support [12].

\section{Physical Examination}

Diagnosis of COPD cannot be made on clinical signs alone, but these may be suggestive of COPD severity [12]. The sensitivity and specificity of a physical examination in detecting mild to moderate COPD are relatively poor due to the slow progressive nature of the disease; there may be no clinical signs or symptoms attributable to aging or smoking [12]. Consequently, COPD is most often diagnosed in the advanced stage when physical signs of airflow obstruction and pulmonary hyperinflation have developed [12]. Chest auscultation may or may not detect crackles or wheezing with a prolonged expiratory phase [12]. Evidence of fatigue, weight loss and anorexia may be noted in severe cases of COPD [12]. Notably, chronic respiratory symptoms may precede airflow limitation and may be associated with the development of acute respiratory events; symptoms may also exist in patients with normal spirometry.

\section{Pulmonary Function Testing}

Spirometry should be performed when COPD is suspected and remains the most sensitive and important test for making a diagnosis of COPD. The GOLD guidelines suggest that in patients with a $\mathrm{FEV}_{1} / \mathrm{FVC}$ ratio $<70 \%$, the presence of a post-bronchodilator $\mathrm{FEV}_{1}$ of $\geq 80 \%, 50 \%$ to $<80 \%, 30 \%$ to $<50 \%$ or $<30 \%$ of the predicted value, presents a mild, moderate, severe or very severe airflow limitation severity in COPD respectively [12].

Diagnosis, Prevention and Treatment of Stable COPD

\section{Combined Assessment}

The updated GOLD guidelines recommend a combined assessment approach to group patients according to airflow, impact of the patient's symptoms on daily living, and patient's future risk of experiencing an exacerbation [12]. The "ABCD" assessment tool has been revised to reflect spirometry-confirmed diagnosis, in conjunction with symptoms and exacerbation history for prognosis and therapeutic considerations (Fig. 1). The ABCD assessment tool allows individual assessment to determine the classification of disease severity and hence achieve better stratification of patients.

\section{Assessment of Severity of Airflow Limitation}

The presence of airflow limitation is indicated by a reduced post-bronchodilator $\mathrm{FEV}_{1} / \mathrm{FVC}$ ratio of $<70 \%$ and an $\mathrm{FEV}_{1}$ of $<80 \%$. The GOLD classification categorizes airflow limitation into stages based on post-bronchodilator $\mathrm{FEV}_{1}$ predictions (Table 2).

\section{Assessment of Symptoms}

The impact of respiratory symptoms on a patient's life should be assessed by the modified Medical Research Council (mMRC) questionnaire and the COPD Assessment Test (CAT ${ }^{\mathrm{TM}}$ ) or the COPD Control questionnaire $\left(\mathrm{CCQ}^{\circledR}\right)[12]$. Shortness of breath during exercise is one of the primary symptoms of COPD, and the mMRC dyspnea scale should be used to grade the breathlessness according to the level of exertion required to elicit it (Table 3) [12]. The CAT and CCQ are simple scoring methods that have a broader coverage of the impact of COPD on the patient's daily life and well-being and correlate closely with health status impairment measured using the more complex St. Georges Respiratory Questionnaire [12]. CAT is a standard and validated assessment tool containing 8 items for the evaluation of the impact of COPD on health status; each response is graded $0-5$ with a higher score indicating worse health status (Table 4) [12]. It has also been translated into several languages and can easily be completed online at www. catestonline.org.

\section{Assessment of Exacerbation Risk}

An exacerbation is defined as an acute worsening of respiratory symptoms resulting in additional therapy. Frequent exacerbations have a high correlation with increased hospitalizations and an increased risk of mortality. Risk of exacerbation is divided into 4 groups (A, B, C, 
Fig. 1. Revised ABCD assessment tool [12]. mMRC, modified Medical Research Council questionnaire; CAT, COPD Assessment Test. ${ }^{\circ}$ GOLD COPD, reproduced with permission.

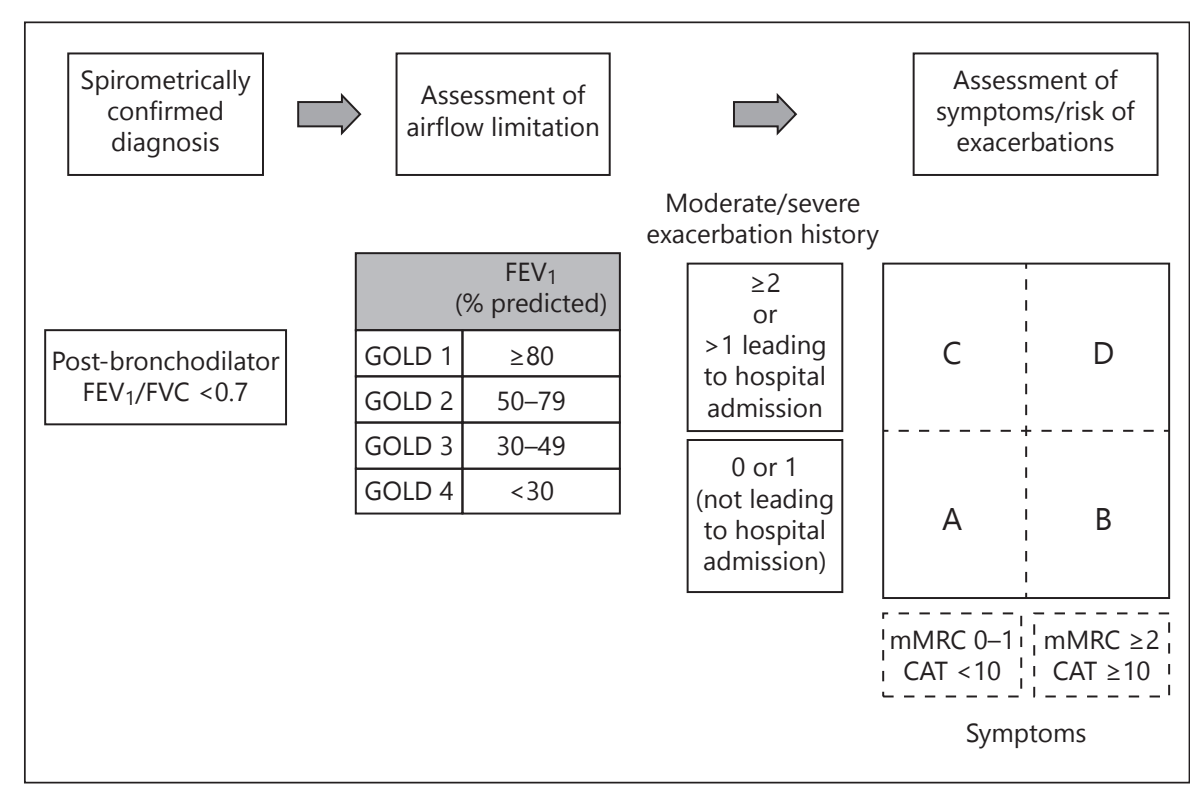

Table 2. Classification of airflow limitation severity in COPD based on post-bronchodilator FEV1 (GOLD staging categories) [12]

In patients with $\mathrm{FEV}_{1} / \mathrm{FVC}<70 \%$

\begin{tabular}{ll}
\hline GOLD staging & spirometric findings \\
\hline 1 (mild) & $\mathrm{FEV}_{1} \geq 80 \%$ predicted \\
2 (moderate) & $50 \% \leq \mathrm{FEV}_{1}<80 \%$ predicted \\
3 (severe) & $30 \% \leq \mathrm{FEV}_{1}<50 \%$ predicted \\
4 (very severe) & $\mathrm{FEV}_{1}<30 \%$ predicted
\end{tabular}

Table 3. The mMRC dyspnea scale

\begin{tabular}{ll}
\hline Grade & Level of breathlessness \\
\hline 0 & No breathlessness, except on strenuous exercise \\
\hline 1 & $\begin{array}{l}\text { Short of breath when hurrying or walking up a } \\
\text { slight hill }\end{array}$ \\
\hline 2 & $\begin{array}{l}\text { Walks slower than contemporaries on level ground } \\
\text { because of breathlessness or has to stop for breath } \\
\text { when walking at own pace }\end{array}$ \\
\hline 3 & $\begin{array}{l}\text { Stops for breath after walking } 100 \text { metres or after a } \\
\text { few minutes on level ground }\end{array}$ \\
\hline 4 & $\begin{array}{l}\text { Too breathless to leave the house, or breathless when } \\
\text { dressing or undressing }\end{array}$
\end{tabular}

Adapted from [12]. mMRC, modified British Medical Research Council questionnaire.
D; Fig. 1). Patients are deemed to have a high exacerbation risk (group C or D) if they have a history of 2 or more exacerbations or more than one exacerbation leading to hospitalization in the past year [12].

Eosinophilia is a good predictor of viral exacerbations [19]. High eosinophil blood counts may predict increased exacerbation rates in patients treated with long-acting beta-agonist (LABA) bronchodilators without inhaled corticosteroids (ICS) [12].

\section{Assessment of Comorbidities}

Patients with COPD are frequently affected by comorbidities, including cardiovascular disease, skeletal muscle dysfunction, metabolic syndrome, osteoporosis, depression, anxiety and lung cancer. Comorbidities potentiate the morbidity of COPD and influence mortality and hospitalizations independently. Routinely monitor and adequately treat comorbidities in all COPD patients. Treatment of comorbidities should not change COPD management [12].

\section{Alpha-1 Antitrypsin Deficiency}

Screening for alpha-1 antitrypsin deficiency (AATD) is recommended for all patients with diagnosed COPD. A low concentration $(<20 \%$ normal) is highly suggestive of homozygous deficiency. Family members should be screened and together with the patient, referred to specialist centres for advice and management [12]. Almost $50 \%$ of the patients with AATD experience more frequent exacerbations than COPD patients without AATD [20]. 
Table 4. COPD assessment test (CAT) [12]

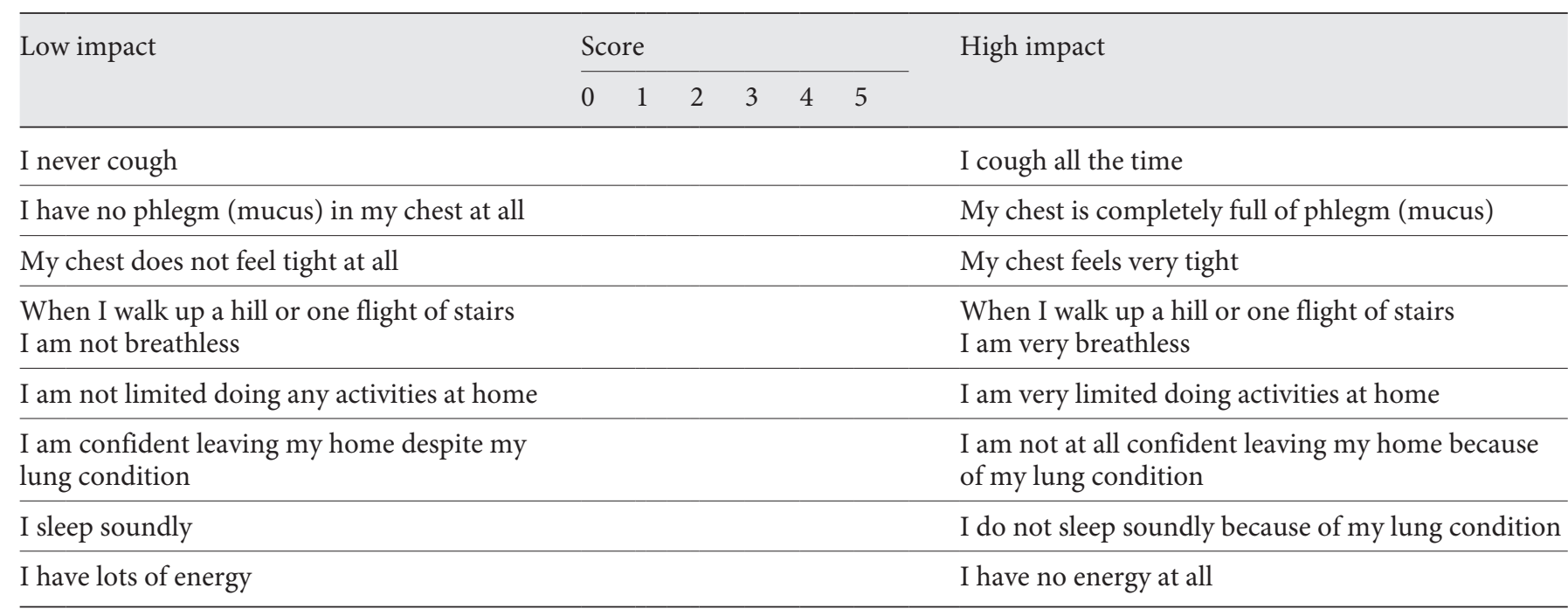

Scores $<10$ are uncommon in the diagnosis of COPD patients and scores $\geq 10$ are very uncommon in healthy persons.

In Switzerland, the mean number of individuals with AATD is estimated at 7,423 based on a population of 7.45 million [21].

\section{Complementary Investigations}

\section{Radiological Imaging}

COPD cannot be diagnosed based on a chest X-ray, but a chest X-ray may be valuable during the initial evaluation to exclude other diseases and to establish the presence of significant comorbidities such as concomitant respiratory, skeletal and cardiac disease [12]. Consider CT of the chest not only for the differential diagnosis, but also for detection of concomitant bronchiectasis, screening for lung cancer, assessment for lung-volume-reduction procedures and lung transplantation [12].

\section{Lung Volumes and Diffusing Capacity}

Pathological changes occurring in COPD can lead to static hyperinflation of the lungs. Measurement of lung volumes by body plethysmography can help characterize COPD severity [12]. Moreover, the evaluation of the residual volume is essential to establish the indication for lung-volume reduction [11]. Measurement of the diffusing capacity of the lungs for carbon monoxide (DLCO) may be considered to provide an index of the severity of tissue destruction in emphysema [22].

\section{Pulse Oximetry}

Pulse oximetry provides a method for rapid assessment of short-term respiratory compromise. It is recommended for all patients with clinical signs suggestive of right heart failure or respiratory failure. Pulse oximetry may be useful in identifying possible hypoxic patients who require supplementary oxygen therapy or in determining which patients require arterial blood gas measurements $[12,23]$.

\section{Exercise Testing}

The objective assessment of exercise capacity in patients with limited exercise tolerance is a useful tool in COPD prognosis, in the assessment of health status, as well as, in the assessment of the effectiveness of pulmonary rehabilitation. The paced shuttle walk test and unpaced 6-min walk test are common test modalities [12].

\section{Composite Scores}

The BODE index assigns scores to 4 variables (body mass index, obstruction, dyspnea and exercise) to give a composite score that better predicts mortality than each single variable [12].

More recently, the B-AE-D index, namely, body mass index (B), frequency of severe acute exacerbations of COPD (AE) and mMRC dyspnea severity (D) has been identified as including the most suitable composite markers for simple and accurate risk assessment in COPD [24]. B-AE-D, plus copeptin, if available, is a COPD-specific prognostic 
Table 5. Differential diagnosis of COPD and asthma [12, 26-29]

\begin{tabular}{|c|c|c|}
\hline \multirow[t]{2}{*}{ Suggestive features } & \multicolumn{2}{|l|}{ Diagnosis } \\
\hline & asthma & COPD \\
\hline Age of onset & $\begin{array}{l}\text { Early onset (typically in childhood); late-onset } \\
\text { asthma is often not Th2 mediated }\end{array}$ & Onset in mid-life \\
\hline History & Family history of asthma; co-existence of obesity & $\begin{array}{l}\text { History of tobacco smoking or exposure } \\
\text { to other types of smoke }\end{array}$ \\
\hline $\begin{array}{l}\text { Th2 high vs. Th2 } \\
\text { low disease }\end{array}$ & $\begin{array}{l}\text { Predominately a Th2-driven disease (with } \\
\text { exception of late-onset asthma), resulting in } \\
\text { increased IgE levels as well as blood and sputum } \\
\text { eosinophil count; eosinophils may decrease in } \\
\text { number in controlled asthma }\end{array}$ & $\begin{array}{l}\text { Predominately a neutrophil-driven disease } \\
\text { (Th2-low disease); eosinophil count may be } \\
\text { increased in some patients }\end{array}$ \\
\hline Pattern of symptoms & $\begin{array}{l}\text { Symptoms vary widely day-to-day; worse at } \\
\text { night/early morning }\end{array}$ & Slowly progressive symptoms \\
\hline $\begin{array}{l}\text { Allergies, rhinitis and/or } \\
\text { eczema }\end{array}$ & $\begin{array}{l}\text { Concomitant allergy, rhinitis and/or eczema } \\
\text { may be present }\end{array}$ & $\begin{array}{l}\text { Not associated with allergies, rhinitis or } \\
\text { eczema }\end{array}$ \\
\hline $\mathrm{FeNO}$ & FeNO is highest in asthma & FeNO is lowest in COPD \\
\hline
\end{tabular}

FeNO, fractional exhaled nitric oxide; IgE, immunoglobulin E; Th2, type 2 helper T-cell.

index that was not inferior to BODE for predicting 2-year all-cause mortality (c-statistic: $0.74,0.77,0.69,0.72$ and 0.63 , respectively; Hosmer-Lemeshow test all $p>0.05$ ) [24].

\section{Differential Diagnosis}

It can be challenging to differentiate between $\mathrm{COPD}$ and asthma with chronic airflow limitation in some patients (Table 5). In patients with common features of both asthma and COPD, a diagnosis of Asthma-COPD Overlap Syndrome or Asthma-COPD Overlap (ACO) may be given. As the role of biologics in the treatment of ACO is still being defined, ACO should be treated according to the dominant phenotype [25]. Additional potential differential diagnoses are easier to distinguish from COPD and include congestive heart failure, bronchiectasis, tuberculosis, obliterative bronchiolitis and diffuse panbronchiolitis [12].

\section{Methodology}

Levels of evidence assigned to management recommendations are based largely on the GOLD report, which uses the evidence-ranking system of the US National Heart, Lung and Blood Institute, and was used in the previous Swiss guidelines (Table 6) [12].

\section{Preventive Therapy}

Prevention and appropriate preventive therapy can alleviate the impact of COPD on public health [12].

\section{Smoking Cessation}

Smoking cessation remains the most effective intervention that reduces lung function decline in COPD and therefore should be the top priority for all COPD patients (Evidence A) [12]. Studies show that smoking cessation slows the annual decrease of $\mathrm{FEV}_{1}$ to a rate comparable to that of non-smokers [30]. In a Swedish study of COPD smokers, the long-term smoking cessation success rate (after 3 years) was $38 \%$ for subjects who took part in smoking cessation groups, compared to only $10 \%$ for subjects in the control group [31]. A systematic review shows that more intensive recruitment strategies that require increased patient contact, improve recruitment of patients into smoking cessation programmes (Evidence A) [32]. Smoking cessation rates also improve when smokers are provided with pharmacotherapy [33].

Pharmacotherapy, including nicotine replacement therapy, is effective in supporting smoking cessation attempts and should be prescribed in the absence of contraindications [12]. A meta-analysis evaluating 7,332 patients with COPD reported that the combination of cognitive behavioural therapy (CBT) and nicotine replacement therapy was 
Table 6. Description of levels of evidence

\begin{tabular}{lll}
\hline $\begin{array}{l}\text { NHLBI evidence } \\
\text { category }\end{array}$ & Sources of evidence & Definition \\
\hline A & $\begin{array}{l}\text { Randomized controlled trials } \\
\text { (RCTs). Rich body of high quality } \\
\text { evidence without any significant } \\
\text { limitation or bias }\end{array}$ & $\begin{array}{l}\text { Evidence is from endpoints of well-designed RCTs that provide a consistent } \\
\text { finding in the population for which the recommendation is made without } \\
\text { any important limitations. Category A requires high quality evidence from } \\
\geq 2 \text { clinical trials involving a substantial number of subjects, or a single high } \\
\text { quality RCT involving substantial numbers of patients without any bias }\end{array}$ \\
\hline B & $\begin{array}{l}\text { RCTs with important limitations. } \\
\text { Limited Body of Evidence }\end{array}$ & $\begin{array}{l}\text { Evidence is from RCTs that include only a limited number of patients, } \\
\text { post-hoc or subgroup analysis of RCTs, or meta-analysis of RCTs. In } \\
\text { general, category B applies when few randomized trials exist, or important } \\
\text { limitations are evident (methodologic flaws, small numbers, short duration, } \\
\text { undertaken in a population that differs from the target population of the } \\
\text { recommendation, or the results are somewhat inconsistent) }\end{array}$ \\
& $\begin{array}{l}\text { Evidence is from outcomes of uncontrolled or non-randomised trials or } \\
\text { from observational studies }\end{array}$ \\
\hline C & $\begin{array}{l}\text { Non-randomized trials, } \\
\text { observational studies }\end{array}$ & $\begin{array}{l}\text { Provision of guidance is deemed valuable but clinical literature addressing } \\
\text { the subject is insufficient. } \\
\text { The panel consensus is based on clinical experience or knowledge that does } \\
\text { not meet the above criteria }\end{array}$ \\
& $\begin{array}{l}\text { Panel consensus, judgement } \\
\text { D }\end{array}$ &
\end{tabular}

NHLBI, National Heart, Lung, and Blood Institute.

the most effective type of intervention (OR 5.08; $p<0.0001$ ) compared to CBT alone (OR $2.8 ; p=0.001$ ) or compared to CBT combined with an antidepressant (OR 3.32; $p=0.002)$ (Evidence A) [34].

Electronic cigarette products are becoming increasingly popular [35]. However, their efficacy and safety are not well defined and thus their widespread use is not advocated [12]. Varenicline [36], bupropion [37] and nortriptyline [38] are recommended in conjunction with supportive intervention programmes to increase longterm smoking cessation rates (Evidence A) [12, 38]. Furthermore, smoking reduces, at least partially, the impact of ICS on $\mathrm{FEV}_{1}$ and peak expiratory flow [39].

\section{Vaccinations}

Patients with COPD are particularly vulnerable to influenza, with evidence for increased incidence and severity of infection [40]. Influenza vaccines are recommended to reduce serious illness and mortality in COPD patients [12]. A Cochrane review reported that an inactivated influenza vaccine reduces the incidence of influenza-related respiratory infections (Evidence B) [41]. Patients with COPD who were administered an inactivated influenza vaccine experienced significantly fewer exacerbations per year than patients with COPD who were administered a placebo [40].

Diagnosis, Prevention and Treatment of Stable COPD
A pneumococcal vaccination provides some protection against community-acquired pneumonia (CAP) and is recommended for all COPD patients $\geq 65$ years of age [12]. For younger COPD patients, the vaccination is recommended if significant comorbidities, such as chronic heart or lung disease, are present [12]. The Federal Office of Public Health recommends a single dose of conjugated 13-valent vaccine (Prevenar-13), with no booster doses [41]. Pneumococcal polysaccharide vaccine (Pneumovax) is no longer recommended because of limited efficacy and because antibody levels may diminish with repeat doses ("immune exhaustion"). A recent systematic review showed that when COPD patients were given the pneumococcal vaccine, they had a lower likelihood of developing CAP compared to COPD patients receiving a control substance (OR 0.62, 95\% CI 0.43-0.89; 6 studies, $n=1,372$; Evidence B) [42]. Pneumococcal vaccination significantly reduced the likelihood of a COPD exacerbation (OR 0.60, 95\% CI 0.39-0.93; 4 studies, $n=446$; Evidence B) [42].

\section{Pharmacological Management of Stable COPD}

None of the existing medications for COPD has been conclusively shown to modify the long-term decline in lung function that is the hallmark of this disease [12]. Spe- 
cifically designed trials are required to confirm the post hoc evidence of such an effect with long-acting bronchodilators and/or ICS [12]. Until then, the main goals with current pharmacotherapy continue to reduce symptoms, reduce frequency and severity of exacerbations and improve exercise tolerance and health status [12].

Treatment should be individualized. Medication choice depends on availability, cost, the patient's preference and clinical response weighed against the side effects [12]. Existing guidelines advocate the use of long-acting bronchodilators as the frontline therapy for COPD, followed by dual combination long-acting bronchodilation if symptoms persistent and regular inhaled corticosteroid therapy is administered as an adjunct in patients experiencing frequent exacerbations. However, the latest longterm data reports that a single inhaler triple therapy with ICS/LABA/long-acting anti-muscarinic agent (LAMA) is superior to standard therapy with a dual combination ICS/LABA or LAMA therapy [43] or tiotropium alone in stable COPD patients [43, 44]. Moreover, escalation from an ICS/LABA or LAMA combination to triple therapy (ICS/LABA/LAMA) using a single inhaler could improve patient adherence to treatment [43,44]. Addition of LAMA to ICS/LABA could improve lung function and patient-reported outcomes [12].

\section{Bronchodilators}

Inhaled bronchodilators are commonly used in the management of airflow obstruction because they exert a direct relaxant effect on bronchial smooth muscle cells, thereby alleviating bronchial obstruction and airflow limitation, reducing hyperinflation and improving exhalation and exercise performance (Evidence A) [45].

The inhalation method is preferred above oral bronchodilators because it maximizes the bronchodilator effect on the airways while minimizing side effects (Evidence A) [12]. There are 3 major classes of inhaled bronchodilators: (1) beta-2-adrenergic agonists (both short- and long-acting), (2) muscarinic receptor antagonists (both short- and long-acting) and (3) systemic phosphodiesterase inhibitors (methylxanthines). Relaxation of bronchial smooth muscle is caused by blocking acetylcholine activity at the receptor (muscarinic antagonists) or stimulating the G-proteincoupled receptor (beta-2-agonists) [46]. Recent guidelines published by the American College of Physicians (ACP), American College of Chest Physicians (ACCP), American Thoracic Society and ERS do not support bronchodilator treatment in asymptomatic COPD patients [47].

Short acting beta-2-agonists (SABAs) and muscarinic antagonists (SAMAs) are equally effective and used for both acute and chronic management of COPD. Regular and as-needed use of SABAs and SAMAs improve FEV and respiratory symptoms (Evidence A) [12]. SABAs have a short duration of action of 4-6 h [12].

A fixed-dose combination of any LABA and LAMA should be considered above monotherapy (Evidence A) [12]. Regardless of the drugs used, LAMA/LABA fixeddose combinations are generally more effective than the respective monotherapies in terms of improvement in trough $\mathrm{FEV}_{1}$, transitional dyspnea index (TDI) and St. Georges Respiratory Questionnaire scores [48]. Compared to treatment with a LABA, LAMA monotherapy has a greater impact on reducing exacerbation rates (Evidence A) and hospitalizations (Evidence B) [12].

A post hoc analysis of the TONADO ${ }^{\circledR}$ studies showed that the once-daily combination of LAMA/LABA (tiotropium/olodaterol) significantly improved lung function in GOLD II, GOLD III and GOLD IV patients, compared to tiotropium alone, irrespective of whether patients had received prior LAMA or LABA maintenance treatment [49]. Further subgroup analyses suggested that this combination should be considered for maintenance therapy in patients with moderate to severe COPD [50].

In general, LABAs and LAMAs are prescribed on a regular basis, as maintenance therapy, to improve lung function, dyspnea and health status and to reduce exacerbation rates (Evidence A) [12]. Twice-daily LABAs such as salmeterol and formoterol have an extended duration of action that is maintained for $12 \mathrm{~h}$ after single dose inhalation [51]. Both SABAs and LABAs are generally well tolerated but may cause resting sinus tachycardia and tremor [52].

Head-to-head trials show that LAMAs are superior to SAMAs for maintenance therapy [53]. LAMA (tiotropium) treatment shows a greater effect on exacerbation rates in clinical trials compared to once-daily LABA (indacaterol) treatment [54]. Dry mouth is one of the most common side effects encountered with LAMAs, attributable to its anticholinergic action [55]. Adverse event rates are similar to placebo in clinical trials [52].

\section{Methylxanthines}

Theophylline is a nonspecific phosphodiesterase inhibitor that can improve lung function, arterial blood gas tensions and walking distance compared to placebo [56]. It has a modest bronchodilator effect on $\mathrm{FEV}_{1}$ and FVC in moderate to severe COPD [57]. Theophylline in combination with beta-2-agonists improves dyspnea more than theophylline monotherapy [58]. In a study by Thomas et al. [59], theophylline plus salbutamol significantly 
improves $\mathrm{FEV}_{1}$ by $31.3 \%$ compared to only 13.5 and $16.2 \%$ with the monotherapies respectively. However, theophylline combined with beta-2-agonists is non-superior to the use of beta-2-agonists alone [58].

\section{Inhaled Corticosteroids}

Compared to placebo, ICS reduces post-bronchodilator $\mathrm{FEV}_{1}$ and exacerbation rate but has no significant effect on mortality [60]. A systematic review, which included data from the large TORCH (TOwards a Revolution in COPD Health) study, shows a smaller improvement in lung function (prebronchodilator $\mathrm{FEV}_{1}$ ) with ICS compared to LABA (MD -18.99 mL; 95\% CI -37.46 to -0.52) and the risk of pneumonia is significantly greater with ICS than with LABA (OR 1.38; 95\% CI 1.10-1.73) [61]. The combination LABA/ICS potentiates the positive effects of the ICS therapy, thus long-term monotherapy with ICS is not recommended for stable COPD (Evidence A) [12]. A meta-analysis of several studies evaluating the combination LABA/ICS shows a significant decrease in exacerbation rate and mortality compared to placebo [62].

Data from the OPTIMO (Real-Life study On the aPpropriaTeness of treatment In MOderate COPD patients) [63] and WISDOM (Withdrawal of Inhaled Steroids during Optimized Bronchodilator Management) [64] trials shows that gradually withdrawing ICS therapy in selected patients with stable COPD at low risk of exacerbation does not increase the risk for exacerbations. Withdrawal of ICS therapy has been suggested in GOLD III COPD patients with normal blood eosinophil count $\left(<150\right.$ eosinophils $\left./ \mathrm{mm}^{3}\right)$ and a limited history of exacerbations ( $<2$ exacerbations per year) $[65,66]$.

In the FLAME trial, the first large, randomized, controlled head-to-head trial assessing combination LABA/ LAMA versus combination LABA/ICS in COPD patients with a history of exacerbations, indacaterol-glycopyrronium (LABA/LAMA) therapy was superior to salmeterol-fluticasone (LABA/ICS) therapy in preventing exacerbations, improving lung function and healthrelated quality of life in COPD patients [67]. However, the IMPACT study, which randomised over 10,000 patients with COPD to LAMA/LABA/ICS (umeclidinium, vilanterol, fluticasone furoate) LAMA/LABA (umeclidinium, vilanterol) and LABA/ICS (vilanterol, fluticasone furoate) for 52 weeks, showed superior outcomes for the combination LABA/ICS as compared to the dual bronchodilation with LABA/LAMA [70]. The fact that most patients were on ICS before inclusion and that "history of asthma" was not an exclusion criteria for the
IMPACT study could partially explain the superiority of LABA/ICS versus LAMA/LABA in IMPACT as much as the exclusion of all patients deteriorating during the run-in phase (on LAMA only) of FLAME could explain the superiority of dual bronchodilation versus LABA/ ICS in that trial. In addition, it is also tempting to hypothesize that the differences in the particular bronchodilators used in FLAME (indacaterol vs. salmeterol) could additionally account for the differences between both regimens. There is consensus that not all patients with COPD will benefit from ICS. Those with more severe disease as assessed by airflow obstruction or respiratory symptoms, those with asthmatic features, as well as those with higher circulating eosinophils counts might profit the most from ICS [12]. Further randomized, prospective studies are needed to validate recommendations related to specific patient populations.

The recent PREVENT study, a recent randomized, placebo-controlled trial including GOLD II-IV patients explored whether increasing the dose of an already established combination treatment (LABA/ICS) at the onset of an upper respiratory tract infection (URTI) could reduce the incidence of subsequent COPD exacerbations for the following 21 days, compared to staying on the low-dose LABA/ICS [68]. Patients receiving low-dose formoterol $(12 \mu \mathrm{g} /$ day $)$ and budesonide $(400 \mu \mathrm{g} /$ day $)$ doubled the doses of LABA/ICS for 10 days following the onset of URTI symptoms. The risk for the development of a severe exacerbation (hospital admission) within 21 days of a URTI was significantly decreased by $72 \%$ compared to the placebo group. COPD patients with more severe disease $\left(\mathrm{FEV}_{1}<50 \%\right)$ or at higher risk (GOLD C and D) also showed a reduction in the risk of exacerbation. Thus, for the first time, a study has shown that hospital admissions can be prevented by targeting URTIs with increased short term LABA/ICS.

\section{Triple Inhaled Therapy}

A randomized study by Aaron et al. [69] showed that combined therapy with fluticasone-salmeterol plus tiotropium may have beneficial effects on quality of life, lung function and hospitalizations without an increase in serious adverse events. Long-term data from the TRILOGY (Single Inhaler Triple Therapy Versus Inhaled Corticosteroid Plus LABA Therapy for COPD) [43] and TRINITY [44] trials demonstrates that single-inhaler triple therapy (ICS/LAMA/LABA) has the propensity to simplify medication regimens, provide greater efficacy, reduce exacerbations and has a greater effect on health-related quality of life than standard treatment. The primary results of the 
TRILOGY study showed a statistically significant improvement in pre-dose $\mathrm{FEV}_{1}$ in the triple therapy group of $0.081 \mathrm{~L}(p<0.001)$ and 2 -h post-dose $\mathrm{FEV}_{1}$ of $0.117 \mathrm{~L}$ $(p<0.001)$ [43]. Adverse events were similar between triple and dual study groups and were typically mild to moderate in severity [43]. TRINITY is a multicentre study evaluating triple therapy in adult patients with severe or very severe COPD [44]. Patients were randomized to 1 of 3 treatment regimens: LAMA alone (tiotropium), fixed triple therapy ICS/LABA/LAMA (beclomethasone/formoterol/glycopyrronium), or triple therapy with ICS/ LABA (beclomethasone/formoterol) plus LAMA (tiotropium) taken separately [44]. The fixed triple combination demonstrated a reduction in moderate and severe exacerbations compared to tiotropium (rate ratio 0.80 [95\% CI $0.69-0.92] ; p=0.0025)$. Non-inferiority between the fixed dose triple therapy and dual combination plus tiotropium was demonstrated, with a mean difference in pre-dose $\mathrm{FEV}_{1}$ of $-0.003 \mathrm{~L}$ (95\% CI -0.033 to 0.027 ) [44]. Recently, triple therapy with LAMA/LABA/ICS proved to be superior to dual bronchodilator therapy with LAMA/LABA, decreasing exacerbation rate by $15 \%$ and showing no association with an increased risk of pneumonia. The IMPACT study confirmed superior outcomes for the triple therapy, LAMA/LABA/ICS (umeclidinium, vilanterol, fluticasone furoate) as compared to LAMA/LABA (umeclidinium, vilanterol) and LABA/ICS (vilanterol, fluticasone furoate) including the rate of moderate or severe exacerbation (0.91 vs. 1.21 and 1.07 per year, respectively) [70]. Mortality was also significantly reduced in patients receiving the triple therapy [70]. The incidence of pneumonia was, however, significantly increased in patients receiving an ICS [70]. Therefore, triple therapy should be considered in selected, symptomatic patients with severe airflow obstruction and at least one exacerbation in the previous year [71].

\section{Oral Corticosteroids}

Oral corticosteroids may improve $\mathrm{FEV}_{1}$ in stable COPD [72]; however; its long-term use is harmful for stable COPD patients because muscle strength and pulmonary function deteriorate after high doses of systemic corticosteroids. A study by Horita et al. [73] reported that long-term oral corticosteroids may increase the mortality of severe and very severe COPD patients.

\section{Phosphodiesterase-4 Inhibitors}

Roflumilast improves lung function and decreases exacerbations (frequency and hospitalizations) in patients with severe to very severe COPD $[74,75]$. The REACT
(Roflumilast in the Prevention of COPD Exacerbations While Taking Appropriate Combination Treatment) study showed that in COPD patients at risk of frequent or severe exacerbations and hospitalizations, receiving inhalation combination ICS/LABA therapy or triple therapy (LAMA/ICS/LABA), roflumilast significantly reduced the rate of severe exacerbations by $24.3 \%(p=0.0175)$ and hospital admissions by $23.9 \%(p=0.0209)$ [74].

\section{Antibiotics}

Although prophylactic antibiotics are not recommended for routine use in patients with COPD, they may be considered in certain situations [12]. A randomized controlled study by Albert et al. reported that adding daily azithromycin $(250 \mathrm{mg})$ to the usual treatment for 1 year decreased the frequency of exacerbations and improved quality of life in patients with COPD aged $\geq 40$ years who had an increased risk of exacerbations (but without hearing impairment) [76]. A more recent study by Uzun et al. [77] confirmed the improvement in exacerbation rate in patients with COPD who received previous treatment for 3 or more exacerbations in the preceding year. Thus, azithromycin $500 \mathrm{mg} 3$ times a week might be considered in patients with severe airflow obstruction and recurrent, frequent exacerbations. Due to the potential side effects (emergence of antimicrobial resistance, gastrointestinal and ontological complaints) the indication for this therapy should be evaluated by a pneumologist.

\section{Alpha-1 Antitrypsin Augmentation Therapy}

It is suggested that this therapy may be considered for never-smokers or ex-smokers with an $\mathrm{FEV}_{1}$ of $35-60 \%$ predicted (Evidence B) [12]. Patients with severe hereditary AATD and established emphysema may also be candidates for alpha-1 antitrypsin augmentation therapy (Evidence B) [12].

\section{Mucolytic and Antioxidant Agents}

Antioxidant mucolytics should be considered in selected patients (Evidence A) [12]. Two meta-analyses demonstrate that long-term mucolytic or antioxidant therapy (e.g., $\mathrm{N}$-acetylcysteine) may significantly reduce the frequency of exacerbations in COPD patients [78, 79]. Improvement of lung function is seen in the 1-year HIACE trial in patients with stable COPD treated with high-dose $\mathrm{N}$-acetylcysteine (600 mg twice daily) [80]. The most benefit is observed in those with frequent exacerbations and only with a high dose of $\mathrm{N}$-acetylcysteine $(1,200$ mg per day) [81]. 


\section{Immunomodulators}

The lyophilized bacterial extract OM-85 BV is an immunomodulator used for preventing exacerbations [82]. There is no conclusive evidence as to its efficacy. One meta-analysis showed that both exacerbation and incidence rate of patients using antibiotics were reduced in COPD patients receiving OM-85 BV compared to placebo by $20 \%$ (relative risk $0.80,95 \%$ CI $0.65-0.97$ ) and $39 \%$ (relative risk $0.61,95 \%$ CI $0.48-0.77$ ) [83], respectively, while a previous meta-analysis found only a numerical trend in favour of OM-85 BV in the exacerbation rate (relative risk $0.83,95 \%$ CI 0.65-1.05) [82]. Further trials are required to confirm the effectiveness of OM-85 BV in patients with COPD [82, 83].

$\mathrm{EPs}^{\circledR} 7630$ is an extract from the roots of the flowering plant Pelargonium sidoides effective for the treatment of URTIs and acute bronchitis. The safety and efficacy of $\mathrm{EPs}^{\circledR} 7630$ for the treatment of patients with stable COPD GOLD II/III is demonstrated in a multicentre, placebocontrolled double-blind study. EPs ${ }^{\circledR} 7630$ prolongs the median time to exacerbation compared to placebo (57 vs. 43 days; $p=0.005$ ) [84]. The number of moderate exacerbations during the treatment period is significantly lower in the EPs ${ }^{\circledR} 7630$ group compared to the placebo group (0.38 [SD 0.53] vs. $0.86[0.68] ; p<0.001)$ [85]. Treatment with $\mathrm{EPs}^{\circledR} 7630$ also results in a reduction in antibiotic use and improvement in quality of life [84-86]. Further trials are required to confirm the effectiveness of $\mathrm{EPs}^{\circledR}$ 7630 in patients with COPD.

\section{Oxygen Therapy}

Long-term oxygen therapy ( $>16 \mathrm{~h}$ per day) is recommended to increase the survival in stable COPD patients with arterial hypoxemia $\left(\mathrm{PaO}_{2} \leq 55 \mathrm{~mm} \mathrm{Hg}\right.$ or $\mathrm{SaO}_{2} \leq 88 \%$, or $55<\mathrm{PaO}_{2}<60 \mathrm{~mm} \mathrm{Hg}$ or $\mathrm{SaO}_{2}=88 \%$ ), if there is evidence of pulmonary hypertension, peripheral oedema suggesting congestive cardiac failure, or polycythemia (haematocrit $>55 \%$; Evidence A) $[12,87]$. In a systematic review of 6 randomized controlled trials, a significant improvement in mortality over 5 years is observed (OR 0.42, 95\% CI 0.18-0.98) for the subjects receiving oxygen therapy compared to those who do not [87].

\section{Pulmonary Rehabilitation}

Pulmonary rehabilitation is one of the key recommended approaches in the treatment of COPD (Evidence A) [12]. It is "a comprehensive intervention based on thorough patient assessment followed by patient tailored therapies that include, but are not limited to, exer- cise training, education, self-management intervention aiming at behaviour change, designed to improve the physical and psychological condition of people with chronic respiratory disease and to promote the long-term adherence to health-enhancing behaviours" $[12,88]$. A meta-analysis of 65 randomized controlled trials involving 3,822 participants concludes that pulmonary rehabilitation, including inspiratory muscle training, improves muscle strength, endurance, exercise capacity, dyspnea, quality of life and emotional function and enhances the sense of control that individuals have over their condition [89]. Pulmonary rehabilitation should be considered for most patients with COPD, although it is especially effective in patients with moderate to severe disease [12]. Programmes lasting 6-8 weeks are recommended for optimal benefit [12].

\section{Interventional Therapy}

Bronchoscopic interventions in COPD patients with advanced emphysema are aimed at reducing hyperinflation and end-expiratory lung volume and at improving exercise tolerance, health status and lung function 6-12 months following treatment [12]. The 2 recommended bronchoscopic procedures are endobronchial valves (Evidence $\mathrm{B}$ ) and lung coils (Evidence B) [12].

Lung volume reduction surgery improves quality of life and survival in patients with severe emphysema and low post-rehabilitation exercise capacity (Evidence A) [12]. However, lung volume reduction surgery is associated with higher costs compared to health-care programs that do not include surgery [12]. Bullectomy results in decreased dyspnoea, improved lung function and exercise tolerance [12].

Lung transplantation improves quality of life and functional capacity in selected patients (Evidence C) [12] .

\section{Pharmacologic Treatment Algorithms}

The GOLD guidelines propose new treatment algorithms for the initiation and subsequent escalation/de-escalation of pharmacological management of stable COPD according to the individualized assessment of symptoms and risk of exacerbations (groups A-D) [12]. A summary is shown in Figure 2. Bronchodilators are recommended as the initial treatment for all groups (Evidence A) [12]. Longacting bronchodilators are preferred over short-acting agents except for patients with only occasional dyspnea (Evidence A) [12]. Patients in group B with persistent dyspnea should escalate to 2 bronchodilators (Evidence A) [12]. For patients in group $\mathrm{C}$, a second long-acting bronchodilator is the preferred treatment option if exacerba- 


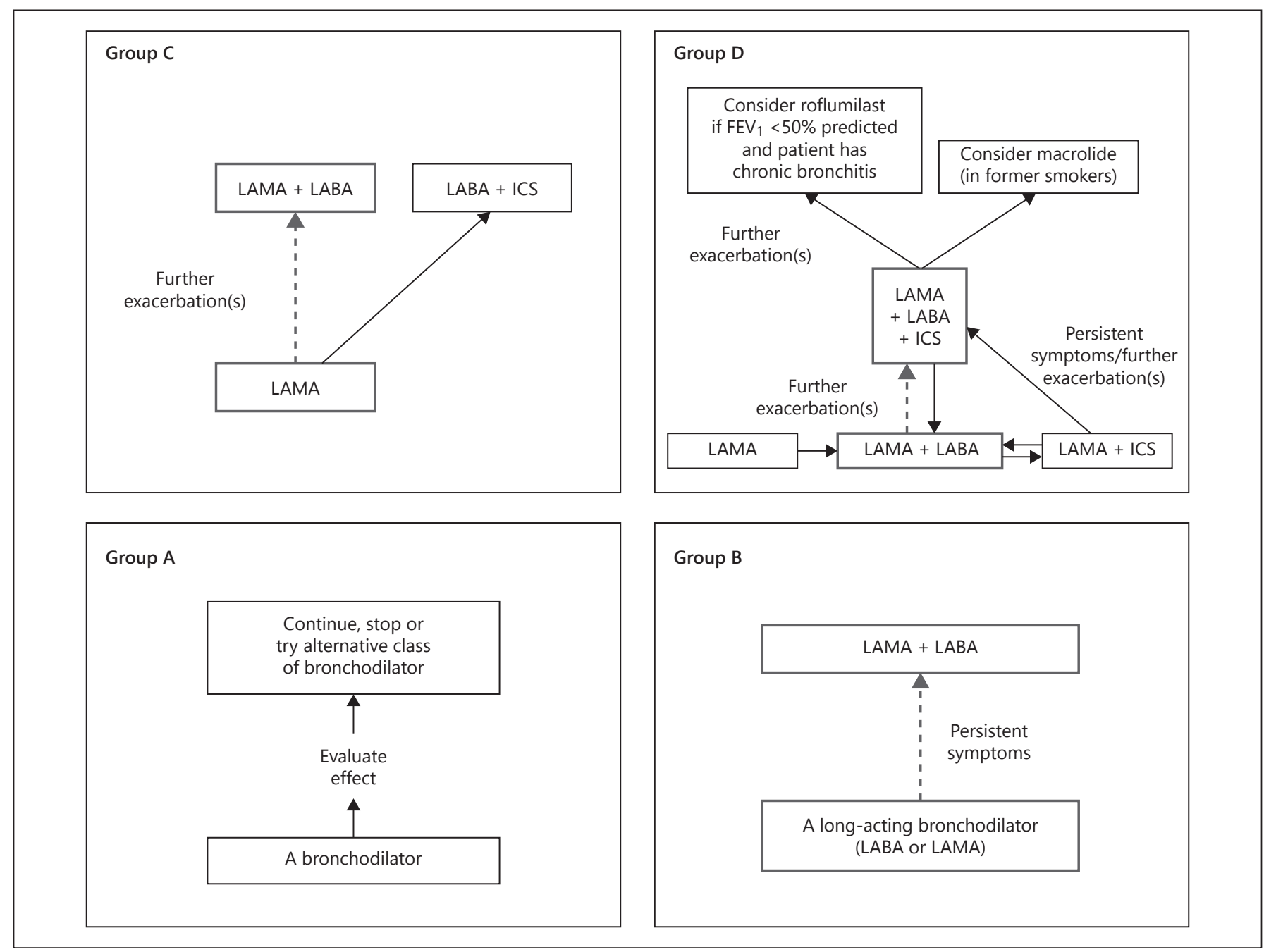

Fig. 2. Pharmacologic treatment algorithms by GOLD Grade [12]. Preferred treatment = --->. In patients with a major discrepancy between the perceived level of symptoms and severity of airflow limitation, further evaluation is warranted.

tions persist [12]. Alternatively, LABA/ICS can be considered (Evidence A) [12]. For group D, treatment can be escalated to triple inhaled therapy (ICS/LAMA/LABA) [12]. Treatment with a macrolide antibiotic (azithromycin $3 \times$ per week) can be considered in former smokers, particularly in frequent exacerbators and those requiring longterm oxygen therapy (Evidence B) and PDE-4 inhibitors (roflumilast) in patients with an $\mathrm{FEV}_{1}<50 \%$ predicated and chronic bronchitis (Evidence B) [12].

Alpha-1 antitrypsin augmentation therapy may be considered for patients with severe hereditary AATD and established emphysema (Evidence B) [12]. Treatment options not recommended for any group include long-term ICS monotherapy (Evidence A), long-term therapy with oral corticosteroids (Evidence A) and theophylline, unless other long-acting bronchodilators are unavailable (Evidence B) [12].

\section{Management of Exacerbations}

An acute exacerbation of COPD (AECOPD) is defined as an acute worsening of respiratory symptoms, and this results in additional therapy [12]. Some COPD patients are particularly susceptible to frequent exacerbations (defined as 2 or more exacerbations per year), and these patients have a worse health status and a higher morbidity than patients with less frequent exacerbations do. The 
goals of management of AECOPDs are to minimize the impact of the current exacerbation and to prevent the development of subsequent events [12].

AECOPDs impose a substantial burden on the healthcare system and cause considerable morbidity, hospital admissions, and mortality. The risk of mortality increases by $30-43 \%$ within 12 months following an acute COPD exacerbation. Among individuals with COPD, some patients are prone to frequent exacerbations while others remain relatively protected [89]. Approximately $70-80 \%$ of COPD exacerbations are triggered by bacterial and viral infections (especially rhinovirus), but air pollution can also be an induction factor $[90,91]$. Frequency of exacerbations is one of the most important determinants of health-related quality of life in patients with COPD.

In Switzerland, patients with AECOPDs have a prolonged hospital stay compared to patients in other European countries (11.3 vs. 8.7 days; $p<0.001$ ) [92]. Moreover, the risk of in-hospital death (5.4\%) is slightly elevated compared to other European countries (4.9\%) but overall mortality is lower ( 8.1 vs. $10.9 \%$, respectively) [92]. The recent European COPD audit recommends at least a (venous) blood gas analysis in every patient admitted to hospital with suspected severe exacerbation of COPD [92]. Currently, the number of arterial blood gas samples taken to assess the severity of exacerbations in Switzerland is comparable to other European countries (85.6 vs. $84.1 \%$, respectively) [92]. Spirometry should also be performed before a patient is discharged from hospital or at least 4-6 weeks thereafter [92].

\section{Preventive Strategies}

Almost half (43\%) of Swiss COPD patients admitted to hospital due to an acute exacerbation are smokers in contrast to $31 \%$ in other European countries $(p<0.001)$ [92]. Based on the recommendations of the European COPD audit, smoking cessation should be offered to COPD patients admitted to hospital for an exacerbation [92]. In addition, patients should be informed about influenza and pneumococcal vaccinations [92].

\section{Bronchodilation}

The mainstay of AECOPD treatment is bronchodilation with SABAs, with or without short-acting anticholinergics (Evidence C) [12]. Medical staff should be trained in the administration of inhaled and nebulized bronchodilators in all Swiss hospitals [92]. A recent European audit suggests that only $79 \%$ of patients in Swiss hospitals receive this treatment for exacerbations at admission [92].

Diagnosis, Prevention and Treatment of Stable COPD

\section{Systemic Glucocorticosteroids}

High-quality evidence supports the treatment of AECOPD with systemic glucocorticosteroids (oral or parenteral route) (Evidence A) [92, 93]. In diagnosed patients, systemic glucocorticosteroids reduce the likelihood of treatment failure and relapse by one month, shorten the hospital stay in patients not requiring assisted ventilation and provide earlier improvement in lung function and symptoms [12,93]. Glucocorticosteroid treatment should not be given for more than 5-7 days [94].

\section{Antibiotics}

AECOPDs should not be treated with antibiotics, unless a bacterial infection is suspected, or the patient requires treatment in the intensive care unit (Evidence B) $[12,95]$. In acute exacerbations of COPD with increased cough and sputum purulence, the use of antibiotics reduces the short-term risk of mortality by $77 \%$ and decreases the risk of treatment failure by 53\% [96]. In nonfebrile exacerbations, antibiotics do not reduce treatment failure at 28 days [97] do not prolong the exacerbationfree time [98]. Antibiotic treatment should not exceed 5-7 days during an AECOPD [12, 99]. A serum procalcitonin-guided approach can reduce use and exposure to antibiotics without impacting clinical outcomes such as re-exacerbation, need for hospitalization or mortality (Evidence A) [100, 101].

\section{Other Recommended Pharmacological Treatments for AECOPD}

Methylxanthines are not recommended for treatment of AECOPD in the GOLD guidelines (Evidence B) [12, 102]. A meta-analysis evaluating the role of intravenous aminophylline during an AECOPD did not find any beneficial effect in terms of improvement of pulmonary function or symptoms [102].

\section{Oxygen Therapy}

Oxygen therapy is a key component of hospital treatment for an exacerbation [12]. Titrating oxygen therapy to $\geq 90 \%$ saturation is recommended in patients with an AECOPD to avoid hypoxemia and to reduce the risk of oxygen-induced hypercapnia $[12,103]$. In Switzerland, approximately $93.1 \%$ of AECOPD patients receive oxygen therapy on admission to hospital.

\section{Non-Pharmacological Therapy}

Non-invasive ventilation (NIV) is the standard of care to decrease intubation rates and mortality in patients hospitalized with AECOPD and acute respiratory 
failure [12]. NIV should be the first mode of ventilation used in COPD patients with acute respiratory failure who have no absolute contraindication because it improves gas exchange, reduces the work of breathing and the need for intubation, decreases hospitalization duration and improves survival (Evidence A) [12]. NIV is effective in reducing the need for invasive mechanical ventilation and improving short-term survival in patients with severe AECOPD. Results from a large retrospective cohort study show that NIV given to patients on admission to hospital reduces in-patient mortality, shortens length of hospital stay and lowers costs compared to those treated with invasive mechanical ventilation [104].

\section{Acknowledgements}

Editorial assistance was provided by Ellen Heitlinger, $\mathrm{H}+\mathrm{O}$ communications Ltd.

\section{Financial Disclosure and Conflict of Interest}

The ERS COPD Audit in Switzerland and the compilation of the Swiss COPD Recommendations were supported by the following institutions: the ERS, AstraZeneca, GlaxoSmithKline, Boehringer Ingelheim, Novartis, Almirall and Schwabe Pharma AG. The financial support received was used for data collection, organisation of workshops for discussion among experts and compilation of manuscripts related to the recommendations. The funding sources had no role in the design, execution, analyses, interpretation of the data or decision to submit the manuscript.

\section{References}

1 National Institute for Health and Clinical Excellence (NICE): Chronic Obstructive Pulmonary Disease in Over 16s: Diagnosis and Management, 2010.

2 Vogelmeier C, et al: [Guidelines for the diagnosis and therapy of COPD issued by Deutsche Atemwegsliga and Deutsche Gesellschaft fur Pneumologie und Beatmungsmedizin]. Pneumologie 2007;61:e1-e40.

3 Société de Pneumologie de Langue Française: [Recommendation for the clinical practice management of COPD]. Rev Mal Respir 2010; 27:522-548.

4 Geijer RM, et al: [The NHG guidelines "Adult asthma" and "COPD"]. Ned Tijdschr Geneeskd 2015;159:A9076.

5 Kankaanranta H, et al: Diagnosis and pharmacotherapy of stable chronic obstructive pulmonary disease: the finnish guidelines. $\mathrm{Ba}$ sic Clin Pharmacol Toxicol 2015;116:291307.

6 Sliwinski P, et al: [Polish respiratory society guidelines for chronic obstructive pulmonary disease]. Pneumonol Alergol Pol 2014;82:227263.

7 Bettoncelli G, et al: The clinical and integrated management of COPD. An official document of AIMAR (Interdisciplinary Association for Research in Lung Disease), AIPO (Italian Association of Hospital Pulmonologists), SIMER (Italian Society of Respiratory Medicine), SIMG (Italian Society of General Medicine) Multidiscip Respir Med 2014;9:25.

8 Miravitlles M, et al: Spanish guideline for COPD (GesEPOC). Update 2014. Arch Bronconeumol 2014;50(suppl 1):1-16.

9 Koblizek V, et al: Chronic Obstructive Pulmonary Disease: official diagnosis and treatment guidelines of the Czech Pneumological and Phthisiological Society; a novel phenotypic approach to COPD with patient-oriented care. Biomed Pap Med Fac Univ Palacky Olomouc Czech Repub 2013;157:189-201.
10 Diagnosis and Treatment of Chronic Obstructive Pulmonary Disease. Portugal, Health Ministry, 2011.

11 Russi EW, et al: Diagnosis and management of chronic obstructive pulmonary disease: the Swiss guidelines. Official guidelines of the Swiss Respiratory Society. Respiration 2013; 85:160-174.

12 Global Strategy for the Diagnosis, Management, and Prevention of Chronic Obstructive Pulmonary Disease, Global Initiative for Chronic Obstructive Lung Disease (GOLD) 2018. http://goldcopd.org.

13 European COPD Coalition. Prevalence in EU. 2017. http://www.copdcoalition.eu/aboutcopd/prevalence (cited February 6, 2017).

14 Baty F, et al: Comorbidities and burden of COPD: a population based case-control study. PLoS One 2013;8:e63285.

15 Abu Hussein N, et al: GPs based Swiss chronic obstructive pulmonary disease (COPD) cohort: disease management in primary care: descriptive data. Eur Respir J 2015;46(suppl 59):PA3867.

16 Bridevaux PO, et al: Prevalence of airflow obstruction in smokers and never-smokers in Switzerland. Eur Respir J 2010;36:12591269.

17 Vicedo-Cabrera AM, et al: Cardiorespiratory hospitalisation and mortality reductions after smoking bans in Switzerland. Swiss Med Wkly 2017;146:w14381.

18 Lisspers $\mathrm{K}$, et al: The economic burden of COPD in a Swedish cohort: the ARCTIC study. Int J Chron Obstruct Pulmon Dis 2018; 13:275-285.

19 Papi A, et al: Infections and airway inflammation in chronic obstructive pulmonary disease severe exacerbations. Am J Respir Crit Care Med 2006;173:1114-1121.

20 Russi EW: Alpha-1 antitrypsin: now available, but do we need it? Swiss Med Wkly 2008;138: 191-196.
21 Blanco I, et al: Estimated numbers and prevalence of PI*S and PI*Z alleles of alpha1-antitrypsin deficiency in European countries. Eur Respir J 2006;27:77-84.

22 Saure EW, et al: Diffusion capacity and CT measures of emphysema and airway wall thickness - relation to arterial oxygen tension in COPD patients. Eur Clin Respir J 2016;3:29141.

23 International COPD Coalition, Clinical Use of Pulse Oximetry: Pocket Reference, 2010,pp $1-8$.

24 Boeck L, et al: Prognostic assessment in COPD without lung function: the B-AE-D indices. Eur Respir J 2016;47:1635-1644.

25 Hines KL, Peebles RS Jr: Management of the Asthma-COPD Overlap Syndrome (ACOS): a review of the evidence. Curr Allergy Asthma Rep 2017;17:15.

26 Barnes PJ: Therapeutic approaches to asthma - chronic obstructive pulmonary disease overlap syndromes. J Allergy Clin Immunol 2015;136:531-545.

27 Barnes PJ: Immunology of asthma and chronic obstructive disease. Nat Rev Immunol 2008;8:183-192.

28 Nair P: What is an "eosinophilic phenotype" of asthma. J Allergy Clin Immunol 2013;132: 81-83.

29 Rogliani P, et al: Airflow obstruction: is it asthma or is it COPD? Int J Chron Obstruct Pulmon Dis 2016;11:3007-3013.

30 Lee PN, Fry JS: Systematic review of the evidence relating FEV1 decline to giving up smoking. BMC Med 2010;8:84.

31 Sundblad BM, Larsson K, Nathell L: High rate of smoking abstinence in COPD patients: Smoking cessation by hospitalization. Nicotine Tob Res 2008;10:883-890.

32 Marcano Belisario JS, et al: Interventions for recruiting smokers into cessation programmes. Cochrane Database Syst Rev 2012; 12:CD009187. 
33 van der Meer RM, et al: Smoking cessation for chronic obstructive pulmonary disease. Cochrane Database Syst Rev 2003;2:CD002999.

34 Strassmann R, et al: Smoking cessation interventions in COPD: a network meta-analysis of randomised trials. Eur Respir J 2009; 34:634-640.

35 Polosa R, et al: Evidence for harm reduction in COPD smokers who switch to electronic cigarettes. Respir Res 2016;17:166.

36 Tashkin DP, et al: Effects of varenicline on smoking cessation in patients with mild to moderate COPD: a randomized controlled trial. Chest 2011;139:591-599.

37 Tashkin $\mathrm{D}$, et al: Smoking cessation in patients with chronic obstructive pulmonary disease: a double-blind, placebo-controlled, randomised trial. Lancet 2001;357:1571-1575.

38 Cahill K, et al: Pharmacological interventions for smoking cessation: an overview and network meta-analysis. Cochrane Database Syst Rev 2013;5:CD009329.

39 Chalmers GW, et al: Influence of cigarette smoking on inhaled corticosteroid treatment in mild asthma. Thorax 2012;57:226-230.

40 Poole PJ, et al: Influenza vaccine for patients with chronic obstructive pulmonary disease. Cochrane Database Syst Rev 2006; 1:CD002733.

41 Bundesamt für Gesundheit (BAG), Pneumokokkenimpfung: Empfehlungen zur Verhinderung von invasiven Pneumokokkenerkrankungen bei Risikogruppen. BAG Bulletin 2014;8:129-141.

42 Walters JA, et al: Pneumococcal vaccines for preventing pneumonia in chronic obstructive pulmonary disease. Cochrane Database Syst Rev 2017;1:CD001390.

43 Singh D, et al: Single inhaler triple therapy versus inhaled corticosteroid plus long-acting $\beta 2$-agonist therapy for chronic obstructive pulmonary disease (TRILOGY): a doubleblind, parallel group, randomised controlled trial. Lancet 2016;388:963-973.

44 Vestbo J, et al: Single inhaler extrafine triple therapy versus long-acting muscarinic antagonist therapy for chronic obstructive pulmonary disease (TRINITY): a double-blind, parallel group, randomised controlled trial. Lancet 2017;389:1919-1929.

45 Cazzola M, Page C: Long-acting bronchodilators in COPD: where are we now and where are we going? Breathe 2014;10:110-120.

46 Cazzola M, et al: Pharmacology and therapeutics of bronchodilators. Pharmacol Rev 2012; 64:450-504

47 Qaseem A, et al: Diagnosis and management of stable chronic obstructive pulmonary disease: a clinical practice guideline update from the American College of Physicians, American College of Chest Physicians, American Thoracic Society, and European Respiratory Society. Ann Intern Med 2011;155:179-191.

48 Calzetta L, et al: A systematic review with meta-analysis of dual bronchodilation with LAMA/LABA for the treatment of stable COPD. Chest 2016;149:1181-1196.
49 Ferguson GT, et al: Efficacy of tiotropium + olodaterol in patients with chronic obstructive pulmonary disease by initial disease severity and treatment intensity: a post hoc analysis. Adv Ther 2015;32:523-536.

50 Singh D, et al: Effects of tiotropium + olodaterol versus tiotropium or placebo by COPD disease severity and previous treatment history in the OTEMTO ${ }^{\circledR}$ studies. Respir Res 2016;17:73.

51 Ball DI, et al: Salmeterol, a novel, long-acting beta 2-adrenoceptor agonist: characterization of pharmacological activity in vitro and in vivo. Br J Pharmacol 1991;104:665671.

52 Ejiofor S, Turner AM: Pharmacotherapies for COPD. Clin Med Insights Circ Respir Pulm Med 2013;7:17-34.

53 van Noord JA, et al: A randomised controlled comparison of tiotropium nd ipratropium in the treatment of chronic obstructive pulmonary disease. The Dutch Tiotropium Study Group. Thorax 2000;55:289-294.

54 Decramer ML, et al: Once-daily indacaterol versus tiotropium for patients with severe chronic obstructive pulmonary disease (INVIGORATE): a randomised, blinded, parallelgroup study. Lancet Respir Med 2013;1:524533.

55 Tashkin DP, et al: A 4-year trial of tiotropium in chronic obstructive pulmonary disease. $\mathrm{N}$ Engl J Med 2008;359:1543-1554.

56 Wang $\mathrm{CH}$, et al: (Meta-analysis of efficacy and safety of oral theophylline in chronic obstructive pulmonary disease). Zhonghua Yi Xue Za Zhi 2010;90:540-546.

57 Ram FS, et al: Oral theophylline for chronic obstructive pulmonary disease. Cochrane Database Syst Rev 2002;4:CD003902.

58 Zacarias EC, Castro AA, Cendon S: Effect of theophylline associated with short-acting or long-acting inhaled beta2-agonists in patients with stable chronic obstructive pulmonary disease: a systematic review. J Bras Pneumol 2007;33:152-160.

59 Thomas P, Pugsley JA, Stewart JH: Theophylline and salbutamol improve pulmonary function in patients with irreversible chronic obstructive pulmonary disease. Chest 1992; 101:160-165.

60 Yang IA, et al: Inhaled corticosteroids for stable chronic obstructive pulmonary disease. Cochrane Database Syst Review 2007;2: CD002991.

61 Spencer S, et al: Inhaled corticosteroids versus long-acting beta2-agonists for chronic obstructive pulmonary disease. Cochrane Database Syst Rev 2011;12:CD007033.

62 Nannini LJ, et al: Combined corticosteroid and long-acting beta2-agonist in one inhaler versus placebo for chronic obstructive pulmonary disease. Cochrane Database Syst. Rev 2013;11:CD003794.

63 Rossi A, et al: Withdrawal of inhaled corticosteroids can be safe in COPD patients at low risk of exacerbation: a real-life study on the appropriateness of treatment in moderate
COPD patients (OPTIMO). Respir Res 2014; 15:77.

64 Magnussen $\mathrm{H}$, et al: Withdrawal of Inhaled Glucocorticoids and Exacerbations of COPD. N Engl J Med 2014;371:1285-1294.

65 Chalmers JD: POINT: Should an attempt be made to withdraw inhaled corticosteroids in all patients with stable GOLD $3(30 \% \leq \mathrm{FEV} 1$ $<50 \%$ predicted) COPD? yes. Chest 2018 153:778-782.

66 Pavord ID: COUNTERPOINT: should an attempt be made to withdraw inhaled corticosteroids in all patients with stable GOLD 3 ( $30 \% \leq \mathrm{FEV} 1<50 \%$ predicted) COPD? no. Chest 2018;153:782-784.

67 Wedzicha JA, et al: Indacaterol-glycopyrronium versus salmeterol-fluticasone for COPD. N Engl J Med 2016;374:2222-2234.

68 Stolz D, et al: Intensified therapy with inhaled corticosteroids and LABA at the onset of URTI to prevent COPD exacerbations- a multicentre, randomised, double-blind, placebo-controlled trial. Am J Respir Crit Care Med 2017. doi: 10.1164/rccm.201709-1807OC, [Epub ahead of print].

69 Aaron SD, et al: Tiotropium in combination with placebo, salmeterol, or fluticasone-salmeterol for treatment of chronic obstructive pulmonary disease: a randomized trial. Ann Intern Med 2007;146:545-555.

70 Lipson DA, et al: Once-daily single-inhaler triple versus dual therapy in patients with COPD. New Eng J Med 2018;378:1671-1680.

71 Papi A, et al: Extrafine inhaled triple therapy versus dual bronchodilator therapy in chronic obstructive pulmonary disease (TRIBUTE): a double-blind, parallel group, randomised controlled trial. Lancet 2018;391:1076-1084.

72 Callahan CM, Dittus RS, Katz BP: Oral corticosteroid therapy for patients with stable chronic obstructive pulmonary disease. A meta-analysis. Ann Intern Med 1991;114:216223.

73 Horita N, et al: Evidence suggesting that oral corticosteroids increase mortality in stable chronic obstructive pulmonary disease. Respir Res 2014;15:37.

74 Martinez FJ, et al: Effect of roflumilast on exacerbations in patients with severe chronic obstructive pulmonary disease uncontrolled by combination therapy (REACT): a multicentre randomised controlled trial. Lancet 2015;385:857-866.

75 Fabbri LM, et al: Roflumilast in moderate-tosevere chronic obstructive pulmonary disease treated with longacting bronchodilators: two randomised clinical trials. Lancet 2009; 374:695-703.

76 Albert RK, et al: Azithromycin for prevention of exacerbations of COPD. N Engl J Med 2011;365:689-698.

77 Uzun S, et al: Azithromycin maintenance treatment in patients with frequent exacerbations of chronic obstructive pulmonary disease (COLUMBUS): a randomised, doubleblind, placebo-controlled trial. Lancet Respir Med 2014;2:361-368. 
78 Cazzola $\mathrm{M}$, et al: Influence of $\mathrm{N}$-acetylcysteine on chronic bronchitis or COPD exacerbations: a meta-analysis. Eur Respir Rev 2015; 24:451-461.

79 Poole P, Black PN: Mucolytic agents for chronic bronchitis or chronic obstructive pulmonary disease. Cochrane Database Syst Rev 2006;3:CD001287.

80 Tse HN, et al: High-dose N-acetylcysteine in stable COPD: The 1-year, double-blind, randomized, placebo-controlled HIACE study. Chest 2013;144:106-118

81 Cazzola M, et al: Impact of mucolytic agends on COPD excacerbations: a pair-wise and network meta-analysis. COPD 2017;14:552563.

82 Sprenkle MD, et al: Clinical efficacy of OM-85 BV in COPD and chronic bronchitis: a systematic review. COPD 2005;2:167175.

83 Pan L, et al: Effects of OM-85 BV in patients with chronic obstructive pulmonary disease: a systemic review and meta-analysis. J Clin Pharmacol 2015;55:1086-1092.

84 Matthys $\mathrm{H}$, et al: Randomised, double-blind, placebo-controlled trial of EPs 7630 in adults with COPD. Respir Med 2013;107: 691-701.

85 Matthys H, Malek FA: Antibiotic use in patients with COPD receiving EPs 7630 as an add-on treatment. Atemwegs Lungenkrankheiten 2015;41:27-34.

86 Matthys H, Funk P: Pelargonium sidoides preparation EPs 7630 in COPD: health-related quality-of-life and other patient-reported outcomes in adults receiving add-on therapy. Curr Med Res Opin 2018;18:1-7.
87 Cranston JM, et al: Domiciliary oxygen for chronic obstructive pulmonary disease. Cochrane Database Syst Rev 2005;4:CD001744.

88 Spruit MA, et al: An official American Thoracic Society/European Respiratory Society statement: key concepts and advances in pulmonary rehabilitation. Am J Respir Crit Care Med 2013;188:e13-e64.

89 Wan ES, et al: Clinical predictors of frequent exacerbations in subjects with severe chronic obstructive pulmonary disease (COPD). Respir Med 2011;105:588-594.

90 Papi A, et al: Pathophysiology of exacerbations of chronic obstructive pulmonary disease. Proc Am Thorac Soc 2006;3:245-251.

91 Sethi S, Murphy TF: Infection in the pathogenesis and course of chronic obstructive pulmonary disease. N Engl J Med 2008;359:23552365.

92 Buess M, et al: Treatment of COPD Exacerbation in Switzerland - results and recommendations of the European COPD audit. Respiration 2017;94:355-365.

93 Walters JA, et al: Systemic corticosteroids for acute exacerbations of chronic obstructive pulmonary disease. Cochrane Database Syst Rev 2014;9:CD001288.

94 Leuppi JD, et al: Short-term vs conventional glucocorticoid therapy in acute exacerbations of chronic obstructive pulmonary disease: the REDUCE randomized clinical trial. JAMA 2013;309:2223-2231.

95 Stolz D, Tamm M: Discriminate use of antibiotics for exacerbation of COPD. Curr Opin Pulm Med 2009;15:126-132.

96 Ram FS, et al: Antibiotics for exacerbations of chronic obstructive pulmonary disease. Cochrane Database Syst Rev 2006;2:CD004403.
97 Daniels JM, et al: Antibiotics in addition to systemic corticosteroids for acute exacerbations of chronic obstructive pulmonary disease. Am J Respir Crit Care Med 2010;181: 150-157.

98 van Velzen P, et al: Doxycycline for outpatient-treated acute exacerbations of COPD: a randomised double-blind placebo-controlled trial. Lancet Respir Med 2017;5:492499.

99 El Moussaoui R, et al: Short-course antibiotic treatment in acute exacerbations of chronic bronchitis and COPD: a meta-analysis of double-blind studies. Thorax 2008; 63:415-422.

100 Stolz D, et al: Antibiotic treatment of exacerbations of COPD: a randomized, controlled trial comparing procalcitonin guidance with standard therapy. Chest 2007;131:9-19.

101 Mathioudakis AG, et al: Procalcitonin to guide antibiotic administration in COPD exacerbations: a meta-analysis. Eur Respir Rev 2017;26:pii:160073.

102 Barr RG, Rowe BH, Camargo CA Jr: Methylxanthines for exacerbations of chronic obstructive pulmonary disease: meta-analysis of randomised trials. BMJ 2003;327:643.

103 Austin MA, et al: Effect of high flow oxygen on mortality in chronic obstructive pulmonary disease patients in prehospital setting: randomised controlled trial. BMJ 2010; 341:c5462.

104 Lindenauer PK, et al: Outcomes associated with invasive and noninvasive ventilation among patients hospitalized with exacerbations of chronic obstructive pulmonary disease. JAMA Intern Med 2014;174:1982-1993. 